\title{
Effects of divided attention on perceptual and conceptual memory tests: An analysis using a process-dissociation approach
}

\author{
M. SCHMITTER-EDGECOMBE \\ Washington State University, Pullman, Washington
}

\begin{abstract}
In two experiments, the nature of the relation between attention available at learning and subsequent automatic and controlled influences of memory was explored. Participants studied word lists in full and divided encoding conditions. Memory for the word lists was then tested with a perceptually driven task (stem completion) in Experiment 1 and with a conceptually driven task (category association) in Experiment 2. For recall cued with word stems, automatic influences of memory derived using the process-dissociation procedure remained invariant across a manipulation of attention that substantially reduced conscious recollection for the learning episode. In contrast, for recall cued with category names, dividing attention at learning significantly reduced the parameter estimates representing both controlled and automatic memory processes. These findings were similar to those obtained using indirect test instructions. The results suggest that, in contrast to perceptual priming, conceptual priming may be enhanced by semantic processing, and this effect is not an artifact of contamination from conscious retrieval processes.
\end{abstract}

It is generally agreed that memory and learning depend on attention. Studies have consistently shown that as the amount of attention available during initial learning decreases, performance on tests of direct (explicit) memory also declines (e.g., Baddeley \& Hitch, 1974; Baddeley, Scott, Drynan, \& Smith, 1969; Bartz \& Salehi, 1970; Bennet \& Murdock, 1965). During direct memory testing, participants are required to consciously remember information learned during a previous episode (Graf \& Schacter, 1985; Schacter, 1987). Examples of direct memory measures include free recall, cued recall, and recognition. Direct memory testing has been distinguished from indirect (implicit) memory testing. During indirect memory testing (e.g., stem completion, perceptual identification), participants' memory for past events is assessed without invoking their conscious recollection of the learning episode. Memory for prior events is inferred in these tasks from the enhanced tendency of participants to complete test items that do not make explicit reference to a past study episode with previously encountered target stimuli (Greene, 1986). This performance facilitation of the previously encountered stimuli is referred to as priming (Tulving \& Schacter, 1990).

This research was reported in part at the 1995 meeting of the National Academy of Neuropsychology in San Francisco and the 1996 meeting of the Psychonomic Society in Chicago. The author gratefully acknowledges the assistance of Jill McConnell and Brittany Jensen for their assistance in coordinating data collection. The author also thanks Axel Buchner, Larry Jacoby, and Neil Mulligan for their helpful comments on earlier versions of this manuscript. Correspondence should be addressed to M. Schmitter-Edgecombe, Department of Psychology, Washington State University, Pullman, Washington 99164-4820. (email: schmitter-e@wsu.edu).
In contrast to direct memory, the role of attention in indirect memory is currently unclear. Some studies have shown that priming on indirect memory tests is unaffected by manipulations of attention at learning (e.g., Isingrini, Vazou, \& Leroy, 1995; Parkin, Reid, \& Russo, 1990; Parkin \& Russo, 1990), whereas other studies suggest that, in certain situations, indirect memory may be affected by dividing attention at encoding (e.g., Mulligan, 1997; Mulligan \& Hartman, 1996; Schmitter-Edgecombe, 1996a). One such situation may be when indirect tests rely heavily on conceptual as opposed to perceptual processes. Memory tests are said to involve conceptual processing if performance is enhanced by attending to the meaning or conceptual properties of information (e.g., category association, general knowledge questions). In contrast, memory tasks are thought to involve perceptual processing if performance is facilitated by attending to the visual, physical, or nonsemantic aspects of stimuli (e.g., stem completion, perceptual identification; see Blaxton, 1989; Roediger, 1990; Smith \& Branscombe, 1988; Srinivas \& Roediger, 1990). Studies that have investigated performance on perceptual indirect tests suggest that, if the division of attention at encoding does not disrupt identification of the study stimuli, then subsequent perceptual priming is unaffected (see Mulligan \& Hartman, 1996, for a review). Results concerning the role of attention in subsequent conceptual priming have not, however, been as consistent.

Several studies suggest that performance on conceptual indirect tests declines following division of attention at encoding (e.g., Mulligan, 1997, 1998; Mulligan \& Hartman, 1996; Schmitter-Edgecombe, 1996a). In one such study, Mulligan and Hartman (1996) had participants read a list of study words either without distraction or while si- 
multaneously completing a digit-monitoring task. Participants' memory for the words was then tested with either a category association task ${ }^{1}$ (conceptual indirect test) or a category-cued recall task (direct test). The results revealed that dividing attention at encoding decreased production of studied items on both the direct task and the indirect task. In this same study, Mulligan and Hartman also demonstrated that performance on a perceptual indirect test (i.e., word-fragment completion) was not affected by a division of attention at encoding. Schmitter-Edgecombe (1996a) also found suggestive evidence indicating that conceptual priming, as assessed with a category association task, was more affected by an attentional encoding manipulation than perceptual priming, as assessed with tachistoscopic identification and perceptual clarification procedures.

In contrast, other studies suggest that performance on conceptual indirect tests remains invariant to manipulations of attention at encoding (Isingrini et al., 1995; Koriat \& Feuerstein, 1976). For example, Isingrini et al. (1995) had participants of various ages rate their liking for the meaning of words either without distraction or while concurrently performing a consonant monitoring task. Participants' memory for the words was then tested with a conceptual indirect test of category-exemplar production and a corresponding direct test of category-cued recall. The results revealed that dividing attention at encoding significantly impaired cued recall performance, whereas indirect test performance was unaffected by the attentional manipulation.

The question of whether dividing attention at encoding affects conceptual indirect tests differently than perceptual indirect tests and/or differently than direct tests has important implications for theory. On the basis of findings of dissociations between indirect and direct memory measures (e.g., Isingrini et al., 1995), it has been suggested that performance on perceptual and conceptual indirect tests may largely reflect automatic encoding processes, whereas performance on direct memory measures is crucially dependent on attentional resources at learning ( $\mathrm{Ja}$ coby, Toth, \& Yonelinas, 1993; Parkin et al., 1990). This reasoning has also been used to help explain the common findings of normal or near-normal perceptual and conceptual priming in neurologically impaired populations (e.g., amnesics, closed head injury) who exhibit deficits on direct memory measures (e.g., Cermak, Verfaellie, \& Chase, 1995; Mutter, Howard, Howard, \& Wiggs, 1990; Shum, Sweeper, \& Murray, 1996). Preservation of indirect memory in these populations may occur in part because such memory processes are supported mainly by automatic processes at encoding, and automatic processes may remain relatively preserved (Schmitter-Edgecombe, 1996a, 1996b). In contrast, difficulties on direct tests may occur because these patient populations are less able to carry out attention-demanding elaborative processing during learning (Cermak, 1993; Jacoby, Woloshyn, \& Kelley, 1989). If, however, conceptual indirect performance is affected by a division of attention at encoding, then such arguments may need to be modified.

Several factors could conceivably account for the inconsistent findings with respect to the role of attention in conceptual priming. One such factor investigated by Mulligan (1997) was the strength of the divided attention manipulation. Mulligan (1997) had participants study a word list while simultaneously retaining digit-letter strings of varying attentional loads $(0,1,3$, or 5$)$. Participants then completed either a conceptual direct test of category-cued recall or a conceptual indirect test of category association. The results revealed that a mild division of attention reduced performance on the direct test but not the indirect test, whereas a strong division of attention reduced performance on both tasks. Furthermore, the strong division of attention eliminated priming entirely on the conceptual indirect memory measure but not the conceptual direct test. These results suggest that the difficulty of the attentional manipulation may moderate whether or not conceptual indirect tests are affected by a division of attention during learning.

A second factor to consider is the possible influence of intentional retrieval strategies. Because memory tests are not process pure, numerous researchers have voiced concerns that indirect tests may be contaminated by consciously controlled uses of memory (Hamann \& Squire, 1996; Jacoby, 1991; McKone \& Slee, 1997; RichardsonKlavehn \& Bjork, 1988; Toth, Reingold, \& Jacoby, 1994). In relation to conceptual indirect tests, when responses are the product of end-directed, step-by-step procedures that take time to complete, intentional forms of retrieval may be more likely to affect performance than when test responses are assessed through immediate, all-or-nothing processing (Perruchet \& Baveux, 1989). It is therefore possible that, in comparison with perceptual indirect tests, conceptual indirect tests are more easily contaminated by explicit retrieval strategies, making it appear as if they are being affected by a division of attention at encoding. Mulligan and colleagues (Mulligan, 1998; Mulligan \& Hartman, 1996) investigated intentional retrieval in their studies by using posttest questionnaires. After excluding those participants who reported an awareness of the relationship between the study episode and the indirect test, these authors continued to find evidence that conceptual indirect test performances were being affected by a strong division of attention at encoding.

To further investigate the possibility that intentional retrieval strategies may compromise performance on conceptual indirect tests, the present study used the processdissociation procedure (PDP; Jacoby, 1991; see also Jacoby et al., 1993; Toth et al., 1994). Rather than identifying controlled (conscious or explicit) and automatic (unconscious or implicit) memory processes with performance on direct and indirect tests, respectively, the PDP postulates a way to assess the contributions of these two bases for responding within a single task. Additionally, unlike posttest questionnaires, which can be affected by experi- 
menter demands and by distortions in self-report data, the PDP is an objective method that makes inferences from a person's behavior.

Process measurements using the PDP require two memory tests: an inclusion test and an exclusion test. In a stem completion experiment, for example, under inclusion instructions, participants are told to complete the stems with studied words or, if they cannot do so, to complete the stems with the first appropriate word that comes to mind. In the inclusion (I) condition, consciously controlled and automatic components of memory are hypothesized to work together to produce responses. Therefore, a word stem would be completed with a studied word if the participant consciously recollected it $(\mathrm{C})$ or if the participant did not recollect it $(1-C)$ but it came to mind automatically (A). If these two bases of responding are independent, then $\mathrm{I}=\mathrm{C}+\mathrm{A}(1-\mathrm{C})$. In contrast, under exclusion instructions participants are told to complete the stems with words that were not presented on the study list. In the exclusion (E) condition, consciously controlled memory is hypothesized to oppose the tendency of automatic components to produce responses. In this condition, a word stem would be completed with a studied word only if it came to mind automatically (A) and participants failed to consciously recollect it $(1-C)$. Hence, $E=A(1-C)$. By subtracting the probability of incorrectly using studied words on the exclusion test from the probability of correctly using studied words on the inclusion test, an estimate of consciously controlled influences can be derived: $\mathrm{C}=$ $I-E$. An estimate of automatic influences can then be computed as $\mathrm{A}=\mathrm{E} /(1-\mathrm{C})$.

Use of the PDP with the inclusion-exclusion test instructions relies on several assumptions that have been controversial. First, the processes estimated by $\mathrm{C}$ and $\mathrm{A}$ are assumed to be functionally independent (for arguments for and against this assumption, see Cowan \& Stadler, 1996, Curran \& Hintzman, 1995, 1997, Dodson \& Johnson, 1996, Hay \& Jacoby, 1996, Hintzman \& Curran, 1997, Jacoby, Begg, \& Toth, 1997, Jacoby \& Shrout, 1997, Jacoby, Yonelinas, \& Jennings, 1997, Joordens \& Merikle, 1993, and Mulligan \& Hirshman, 1997). Second, consciously controlled recollection is assumed to contribute to performance to the same extent under both inclusion and exclusion test instructions (for discussion, see Graf \& Komatsu, 1994, and Toth, Reingold, \& Jacoby, 1995). Third, the criterion for responding on the basis of automatic influences is assumed to be the same across all experimental conditions being compared.

It is now clear that assumptions underlying the PDP can be violated (see Jacoby, 1998). Jacoby (1998) described a set of conditions that are important for meeting the assumptions of the PDP. These conditions include using task instructions that encourage participants to employ a directretrieval strategy in both the inclusion test condition and the exclusion test condition. Direct-retrieval instructions encourage participants to exclude items only on the basis of recollection and have been shown to result in equivalent base rates across inclusion and exclusion conditions ( $\mathrm{Ja}$ - coby, 1998). Jacoby has demonstrated that use of an alternate generate/recognize strategy can lead to violations of the PDP's assumptions (see Jacoby, 1998). Jacoby also advocated selecting stimuli that produce base rates that are sufficiently high to avoid zeros in the exclusion condition. Estimates of automatic influences can be artificially lowered by participants who score perfectly in the exclusion condition (i.e., zero; see Jacoby, 1991; Toth et al., 1994). Furthermore, the choice between means of dealing with zero scores in exclusion performance remains controversial (see Curran \& Hintzman, 1997; Jacoby, Begg. \& Toth, 1997).

In the present study, the PDP was used to examine the effect that divided attention at encoding has on estimates of automatic and consciously controlled memory processes. The experimental methodology conformed closely to the conditions outlined by Jacoby (1998) as important for meeting the assumptions of the PDP. In two experiments, the amount of attention that participants had available to encode target word lists was varied by having participants study the lists under conditions of both full and divided attention. Memory for the target words was then assessed with a perceptually driven task (stem completion) in Experiment 1 and a conceptually driven task (category association) in Experiment 2. To facilitate comparison across experiments, both experiments used the same study materials and the same divided-attention task. In the dividedattention task, participants were required to read the study words while simultaneously responding on a keyboard to computer-generated auditory digits (e.g., six). The digitresponse task was designated as the participants' primary task, and it was sufficiently difficult to ensure that much less attention was available to process the target words in the divided-attention condition than in the full-attention condition. If attentional resources at learning play little or no role in supporting implicit memory, then, regardless of the memory test's emphasis on perceptual or conceptual processing, automatic estimates of memory derived using the PDP should remain invariant to the attentional manipulation at encoding. However, if the amount of attention available at encoding is important to the processes that support later conceptual priming, then automatic estimates of memory derived for the conceptually driven task should be affected by the attentional encoding manipulation. For comparison purposes, an indirect test condition was also included in Experiments 1 and 2.

\section{EXPERIMENT 1}

The stem completion task is typically classified as a perceptually driven task since performance on this test is facilitated by attending to the perceptual characteristics of stimuli, but not by attending to conceptual characteristics ${ }^{2}$ (Blaxton, 1989; Roediger et al., 1992; Srinivas \& Roediger, 1990). Studies evaluating perceptually driven tasks (e.g., perceptual identification, word-fragment and word stem completion) have shown that dividing attention at learning reduces later recollection for the previously stud- 
ied items but leaves unchanged perceptual priming (e.g., Mulligan \& Hartman, 1996; Schmitter-Edgecombe, 1996a) or automatic influences of memory derived using the PDP (Jacoby et al., 1993; Wolters \& Prinsen, 1997). To the extent that attentional resources at learning (beyond those necessary for identification) play little role in supporting subsequent perceptual priming, I expected to replicate these previous findings.

\section{Method}

\section{Participants and Design}

Seventy-two undergraduate students who received course credit were the participants in this experiment. Half of the participants completed word stems under indirect test instructions; the other half of the participants completed word stems under both inclusion and exclusion test instructions. Word stems presented at test corresponded to (1) words that had been processed in a full-attention encoding condition, (2) words that had been processed in a dividedattention encoding condition, or (3) new words that served as a baseline measure. The participants were tested individually.

\section{Stimuli}

The stimuli were 108 words, five to seven letters in length, ranging in frequency from 1 to 200 per million (Kučera \& Francis, 1967). Eighty-four of these words served as the critical target words. For the indirect test group, the target words were divided into three sets of 28 words each. For any one participant, one set was used in the full-attention condition, another set in the divided-attention condition, and the remaining set in the new condition. Sets were rotated through each of the experimental conditions so that each word served equally often in each condition. For the inclusion-exclusion test group, each of the three sets were further divided into two sets of 14 words. Thus, for the inclusion-exclusion test group, in addition to the conditions described earlier, each word served equally often as a word to be included and a word to be excluded. To avoid primacy and recency effects, 6 words were presented at the beginning and the end of the critical sets administered in the full- and dividedattention conditions. These buffer items stayed constant across the full- and divided-attention conditions.

Anticipating the requirements of Experiment 2, targets consisted of 2 members from each of 42 taxonomic categories, with different categories represented in each of the six sets of 14 target words. Category exemplars were selected from the Battig and Montague (1969) and the Hunt and Hodge (1971) norms. The category exemplars were given by at least 10 participants in one of the normative studies, and they were not among the 4 highest ranked exemplars. The mean normative frequencies of the six sets of target words ranged from 15 to 22 per million.

The stem completion test list contained 84 critical three-letter stems corresponding to the 28 words read under full attention, 28 words read under divided attention, and 28 new words that served as baseline. The test also contained 28 stems corresponding to filler items and 3 stems corresponding to practice items. The filler items were used to equate the number of stems corresponding to old and new items and were not included in the analysis. The test list was pseudorandomized such that there were no more than 2 consecutive items from the same encoding list. Each of the three-letter stems used at test was unique within the experiment but not within the language - that is, each stem could be completed with more than one five- to seven-letter word.

\section{Apparatus}

The target words were presented to the participants on a Power Macintosh personal computer (7100/66). The participants were seated approximately $30 \mathrm{~cm}$ from the computer screen. Each target word was presented in the center of the computer screen in uppercase letters (Geneva, 24-point), subtending approximately $7.2^{\circ}$ of horizontal and $2.0^{\circ}$ of vertical visual angle. The digit-response task required the participants to respond as to whether computergenerated auditory digits were "odd" or "even" by pressing specified keys on a keyboard. Responses were recorded to the nearest millisecond. The words one, two, three, four, five, six, eight, and nine were used in the digit-response task (seven was avoided since it is two syllables).

\section{Procedure}

The experiment was presented in four successive phases: baseline assessment, study phase, distractor test, and memory testing. The baseline, study, and distractor phases were identical for the participants in both the indirect test group and the inclusion-exclusion test group. Appropriate instructions were given before each phase, and the entire session lasted approximately $65 \mathrm{~min}$.

Baseline assessment. Prior to beginning the experiment, the experimenter assessed visual acuity and obtained basic health and demographic information. Next, the participants' baseline performance (mean reaction time [RT] and accuracy) was established on the digit-response task. For this task, the participants were told that they were to respond as to whether computer-generated auditory digits were "odd" or "even" by pressing the " $\mathrm{B}$ " and " $\mathrm{N}$ " keys, respectively, on the keyboard. The participants used the index and middle fingers of the dominant hand to respond. Both speed and accuracy were stressed. To reduce RT latencies, the participants rested their fingers on the appropriate response keys throughout the duration of the task. The sequence for the digit-response task was random, and the rate at which the digits were generated varied randomly between 2.0 and $3.0 \mathrm{sec}$. It was therefore not possible for the participants to anticipate the appearance of a digit or the response required. The digit-response task consisted of 30 practice trials followed by 40 test trials. The practice trials were readministered if the participant had difficulty with the task. Following completion of the test trials, each participant's mean RT and accuracy rates were computed and shown to them.

The participants then practiced performing the digit-response task while simultaneously carrying out a second task. The second task required participants to read out loud common English names (e.g., KEVIN). Each target name was presented in the center of the computer screen for $2.5 \mathrm{sec}$. There was a $1.0-\mathrm{sec}$ fixation stimulus between each target name. The experimenter monitored each participant's responses for errors in reading the names. The participants were told that the name reading task was meant only to interfere with their more important task of responding to the digits. They were told to consider the digit-response task their primary task. Practice trials were repeated until the participants' mean RT and accuracy in the concurrent condition fell within $100 \mathrm{msec}$ and 5 percentage points of their digit-response baseline performance. The participants completed a mode of two practice sets ( 80 trials) and a maximum of three practice sets ( 120 trials) in the divided-attention condition before proceeding to the experimental task.

Study phase. In the experimental study phase, the participants were required to read two lists of 40 target words. Similar to the practice task, each target word was displayed in the center of the computer screen for $2.5 \mathrm{sec}$. There was a 1.0-sec fixation stimulus between each word, and the experimenter monitored and recorded errors in reading the words. Each participant read one word list under the fullattention condition and the other while simultaneously completing the digit-response task. The participants were instructed to watch the computer screen continuously and to read each word out loud carefully since they would later be asked to write a story that incorporated words from the lists. In the dual-task condition, the participants were reminded that they were to keep their mean RT and accuracy rate in the divided-attention condition within $100 \mathrm{msec}$ and 5 percentage points of their baseline digit-response performance. 
Table 1

Baseline and Simultaneous Digit-Response Performances for the Indirect and Inclusion-Exclusion Test Groups in Experiment 1

\begin{tabular}{|c|c|c|c|c|}
\hline \multirow[b]{3}{*}{ Performance Measure } & \multicolumn{4}{|c|}{ Digit-Response Condition } \\
\hline & \multicolumn{2}{|c|}{ Baseline } & \multicolumn{2}{|c|}{ Simultaneous } \\
\hline & $M$ & $95 \% \mathrm{CI}$ & $M$ & $95 \% \mathrm{CI}$ \\
\hline \multicolumn{5}{|c|}{ Indirect Test Group } \\
\hline Reaction time (msec) & 744.46 & $716.64-773.28$ & 818.51 & $789.69-847.33$ \\
\hline Accuracy rate & 97.73 & $96.12-99.34$ & 94.07 & $92.46-95.68$ \\
\hline \multicolumn{5}{|c|}{ Inclusion-Exclusion Test Group } \\
\hline Reaction time (msec) & 745.52 & $719.11-771.93$ & 787.16 & $760.75-813.57$ \\
\hline Accuracy rate & 96.51 & $95.26-97.76$ & 94.45 & $93.20-95.70$ \\
\hline
\end{tabular}

Note-CI, confidence interval.

They were instructed to consider the digit-response task their primary task.

All participants saw two of the three sets of 28 target words during the study phase of the experiment. The three sets were counterbalanced across encoding conditions. Order of administration of the full- and divided-encoding conditions was also counterbalanced across participants.

Distractor test. Following presentation of the target lists, the participants completed the Digit Symbol subtest of the Wechsler Adult Intelligence Scale-Revised (WAIS-R; Wechsler, 1981). This test took approximately 4 min to administer and served as a distractor task.

Memory testing. Following completion of the distractor task, the participants were administered the word-stem completion test. Word stems were presented in uppercase letters in the center of the computer screen. Three practice items that corresponded to buffer words were given at the beginning of the test list. Presentation order of the test list was the same for all participants.

The participants in the indirect test group were told that, for this next task, we were interested in learning more about the types of words that certain letter sequences elicit. They were presented with three-letter stems on the computer and told to complete each stem using the first five- to seven-letter word that came to mind. No proper nouns or plurals were allowed. No mention was made about the relation between the studied words and the stem completion test.

The participants in the inclusion-exclusion test group were told that their memory for the words presented during the study phase of the experiment was to be tested. The participants were presented with three-letter word stems on the computer that were accompanied by either the word old or the word new. The word old or new was presented above and to the left of the word stem. If the word old appeared (inclusion condition), the participants were told that they were to use the word stem as a cue to help them remember a word that had been presented in the earlier word lists that they had read. If they could not think of an old word they were to complete the stem with the first appropriate word that came to mind. If the word new appeared, the participants were told to try to retrieve the studied item but then to complete the word stem with a word that was not presented to them earlier in the experiment. Because directretrieval instructions are important for meeting the PDP's assumptions, the participants were encouraged to first use the stems as cues for direct-retrieval of studied items in both the inclusion condition and exclusion condition (see Jacoby, Yonelinas, \& Jennings, 1997). Additionally, intermixing the old and new test conditions should increase the likelihood of meeting the assumption that recollection is the same for the inclusion and exclusion tests (see Jacoby, 1998; Yonelinas \& Jacoby, 1996; but see Buchner, Erdfelder, \& VaterrodtPlunnecke, 1995, for other methodological concerns with using this within subjects procedure). No proper names or plurals were allowed as stem completions, and all words had to be five to seven letters in length. Half of the word stems representing full encoding, divided encoding, new words (baseline), and filler items were presented with the word old, and half were presented with the word new. Although presentation order of the test stems was the same for all participants, presentation of the words old and new was counterbalanced across two test lists so that each word stem served equally often in the inclusion and exclusion test conditions.

For both the indirect test group and the inclusion-exclusion test group, if the participant's response met the response criteria (i.e., began with three-letter stem, five to seven letters in length, not a proper noun or a plural), the experimenter pressed a key that removed the word stem and initiated the next trial. Otherwise, the participants were informed of their errors and instructed to try to give a satisfactory completion for the stem. The participants were allowed a maximum of $20 \mathrm{sec}$ to complete each word stem. If the stem had not been completed after the allotted time, the computer automatically advanced to the next trial.

Posttest awareness interview. For the indirect test group, following completion of the word-stem task, test awareness was assessed to determine whether intentional forms of processing influenced responses. The participants were first asked open-ended questions about the general strategy they used to complete the word-stem task and what they thought the purpose of the task was. The participants who spontaneously reported an awareness of producing studied words when completing the stem task were then asked whether they had intentionally tried to retrieve studied words when completing the word stems.

\section{Results}

\section{Digit-Response Task}

Table 1 presents the mean and $95 \%$ confidence intervals (CIs) for the baseline and simultaneous digit-response performances (i.e., RT and accuracy rates) as a function of test group. For both the indirect test group and inclusionexclusion test group, the participants were faster and more accurate in the baseline condition than in the simultaneous task condition. These results suggest that the digitresponse task was an attention-demanding task that could not simply be performed automatically with the wordreading task. Both groups were, however, able to keep their concurrent digit-response performance within the expected goal of $100 \mathrm{msec}$ and 5 percentage points of their baseline performance, suggesting that the participants were treating the digit-response task as their primary task in the divided-attention condition. 
Table 2

Probability of Responding with an Old Word and Parameter Estimates of Controlled and Automatic Memory Processes for the Stem Completion Test

\begin{tabular}{cccc}
\hline \multirow{2}{*}{$\begin{array}{c}\text { Performance } \\
\text { Measure }\end{array}$} & $\begin{array}{c}\text { Full } \\
\text { Attention }\end{array}$ & $\begin{array}{c}\text { Study Processing } \\
\text { Divided } \\
\text { Attention }\end{array}$ & New \\
\hline Test & & & \\
$\quad$ Indirect & .30 & .28 & .15 \\
$\quad$ Inclusion & .47 & .32 & .17 \\
Exclusion & .19 & .23 & .17 \\
Estimate & & & \\
Controlled & .28 & .09 & \\
Automatic & $.25(.27)$ & $.25(.26)$ & \\
\hline
\end{tabular}

Note-Numbers in parentheses are estimates computed after removing the data of 3 subjects whose performance was zero in either the full $(n=2)$ or the divided $(n=1)$ exclusion condition. Base rate for inclusion exclusion group $=.17$.

\section{Word-Stem Task}

Table 2 presents the proportion of stems completed with target words under each experimental condition. At study, the participants in both the indirect test group and the inclusion-exclusion test group made few errors in reading the words: 2 errors and 1 error, respectively.

Indirect test analyses. The data from the indirect test group revealed that the probability of completing stems with studied words did not differ between the fullattention $(.30)$ and divided-attention $(.28)$ conditions $[t(35)=1.58, p=.134]$. Completing stems with studied words was also well above baseline (.15) for items encoded in both the full-attention and divided-attention conditions $[t \mathrm{~s}(35)>7.60]$. Consistent with other studies (e.g., Mulligan \& Hartman, 1996; Parkin et al., 1990; SchmitterEdgecombe, 1996a), these results demonstrate that when the identification of study stimuli is not disrupted, dividing attention at learning does not effect subsequent perceptual indirect memory.

Although stem completion performance did not differ significantly between the full- and divided-attention conditions, the descriptive level favored the full-attention (.30) over the divided-attention (.28) condition. Therefore, to further explore the possibility that conscious retrieval strategies may contaminate indirect test performance, I examined responses to the posttest awareness interview. On the posttest interview, 22 participants $(61 \%)$ spontaneously reported an awareness of producing target words when completing the stem task. Of these participants, 18 $(50 \%)$ reported that they had intentionally used conscious retrieval when completing the stem task, and they were labeled as intentional. The remainder of the participants $(n=18)$, those who were unaware of the relationship or reported no intentional retrieval usage, were labeled as unintentional. A comparison of the performances of these two groups revealed that, for the intentional retrievers, the probability of completing stems with studied words was greater in the full-attention condition (.34) than in the divided-attention condition $(.28)[t(17)=2.95, p<01]$.
For the unintentional retrievers, the probability of completing stems with studied words did not differ between the full-attention (.27) and divided-attention (.28) conditions $[t(17)=-.65]$. These results indicate that conscious retrieval strategies can contaminate performance on indirect tests and that inaccurate conclusions can be reached if the majority of participants utilize intentional retrieval strategies.

PDP analyses. The data from the inclusion-exclusion group were submitted to a $2 \times 2$ analysis of variance (ANOVA) with test instruction (inclusion and exclusion) and encoding condition (full and divided) as withinsubject factors. The analysis revealed main effects of test instruction $\left[F(1,35)=81.84, M S_{\mathrm{e}}=1.23, p<.001\right]$ and encoding condition $\left[F(1,35)=8.30, M S_{\mathrm{e}}=0.10, p<.01\right]$. More important, the two factors interacted $[F(1,35)=$ $\left.31.75, M S_{\mathrm{e}}=0.31, p<.001\right]$. The probability of completing stems with studied words in the inclusion condition was higher for words processed in the full-attention condition, than in the divided-attention condition (.47 vs. .32) $[t(35)=5.64, p<.001]$, but this pattern of performance was reversed in the exclusion condition (.19 vs. .23) $[t(35)=$ $-1.81, p<.08)$. These results indicate that the participants were better able to include (inclusion) and exclude (exclusion) target words that were processed in the fullattention condition than in the divided-attention condition.

Before computing the estimates of $\mathrm{C}$ and $\mathrm{A}, \mathrm{I}$ checked to see whether response strategies differed across the inclusion and exclusion test instructions (see Jacoby et al., 1993; but see Dodson \& Johnson, 1996). Jacoby and his colleagues (Jacoby, 1998; Yonelinas \& Jacoby, 1996) have argued that if base rates do not differ and one's interest is in dissociations, then a model of response bias is unnecessary. Because stems for new words (base rate) were completed equally often in the inclusion (.17) and exclusion (.17) conditions, I used the process-dissociation formulas described earlier to calculate the estimates of $\mathrm{C}$ and $\mathrm{A}$. These values showed that divided attention, relative to full attention, during study reduced the probability of later consciously controlled recollection $(\mathrm{C}=.09$ vs. .28$)[t(35)=$ $5.64, p<.001]$. In contrast, estimates of A remained invariant to the attentional manipulation $(\mathrm{A}=.25$ vs. .25$)$ $[t(35)=0.10, p>.90]$. Estimates of A were also significantly above baseline (.17) for both the full-attention and the divided-attention condition $[t \mathrm{~s}(35)>10.40]$.

In the exclusion test condition, 3 participants produced no intrusions of items that had been studied in either the full-attention condition $(n=2)$ or the dividedattention condition $(n=1)$. Because estimates of A can be artificially lowered by participants who score perfectly in the exclusion condition (i.e., zero; see Jacoby, 1991; Toth et al., 1994), I recalculated the automatic contributions after eliminating the data of the 3 participants who had produced floor effects (but see Curran \& Hintzman, 1997). This resulted in A estimates of .27 in the fullencoding condition and .26 in the divided-encoding condition. These estimates of $A$ are thought to reflect the additive effects of the automatic influences of memory for 
the specific study episode and the base rate probability of completing the stems (see Jacoby et al., 1993). Therefore, an index of the automatic influences produced by our specific study experience was derived by subtracting baseline performance (new items) from the estimates of A for the studied words. A comparison of the adjusted estimates in the full-attention (.10) and divided-attention (.09) conditions again revealed that the parameters representing automatic influences on stem completion were not significantly affected by a division of attention at encoding $[t(32)=0.18]$.

\section{Discussion}

Consistent with previous PDP studies (e.g., Jacoby et al., 1993; Wolters \& Prinsen, 1997), the results revealed that, for recall cued with word stems, decreasing the amount of attention available at learning reduced the parameter estimates of $\mathrm{C}$ but had no significant effect on estimates of A. Results from the indirect test also showed that reducing attention at learning had no effect on perceptual priming. Currently, perceptual repetition priming is thought to reflect a more rapid and/or efficient perceptual reprocessing of a stimulus that is due to recent perceptual processing of the stimulus (e.g., Schacter, 1990; Tulving \& Schacter, 1990). Studies using positron emission tomography have found that, following exposure to a stimulus, less neural activity is required because subsequent processing of the stimulus is perceptually more efficient (Buckner et al., 1995; Squire et al., 1992). Several studies also suggest that perceptual priming reflects changes in earlystage, presemantic processing systems that may precede those required for establishing declarative memory (Bentin, Moscovitch, \& Heth, 1992; Haist, Musen, \& Squire, 1991). The results of the present experiment are consistent with the idea that these perceptual, presemantic activation processes do not require significant attentional resources during learning to support later perceptual priming.

\section{EXPERIMENT 2}

Experiment 2 was identical to Experiment 1 with the exception that memory for the target words was assessed using a conceptually driven task (i.e., category association). The category association test is typically classified as a conceptually driven task since performance on this task is facilitated by attending to the meaning or conceptual properties of information, but not by attending to the perceptual characteristics of stimuli (Blaxton, 1989; Roediger, 1990; Srinivas \& Roediger, 1990). The question of primary interest was whether reducing attention available at learning would affect automatic estimates of memory at retrieval derived using the PDP when retrieval was cued with category names. It has recently been argued that, unlike perceptual priming, some amount of postperceptual (presumably semantic) processing is required in order to find priming on the category association test (Mulligan \& Hartman, 1996). If semantic processing is important for later conceptual priming, and if dividing attention at encoding reduces the amount of semantic processing during learning (see e.g., Craik, 1983; Craik \& Byrd, 1982), then the magnitude of conceptual priming may decrease when attention is divided at encoding. However, if previous findings demonstrating that conceptual priming is affected by an attentional encoding manipulation were a result of contamination by intentional retrieval mechanisms, then automatic estimates of memory computed using the PDP should remain invariant to the divided-attention manipulation.

\section{Method \\ Participants and Design \\ Seventy-two undergraduate students participated in this experi- ment and earned course credit. Thirty-six of the participants com- pleted the category association test under indirect test instructions and the remaining 36 participants completed the task under both in- clusion and exclusion test instructions. The categories presented at test corresponded to (1) category exemplars that had been pro- cessed in a full-attention encoding condition, (2) category exem- plars that had been processed in a divided-attention encoding con- dition, or (3) novel category exemplars that served as a baseline measure. The participants were tested individually.}

\section{Stimuli}

To render this experiment as comparable as possible to Experiment 1 , the same apparatus, study lists, divided-attention task, and distractor task were used. Only the test list differed from that used in Experiment 1 . The test list contained 42 category names corresponding to the 28 category exemplars read under full encoding, 28 category exemplars read under divided encoding, and 28 new category exemplars that served as baseline. The test list also contained 14 category names corresponding to filler items and 3 category names corresponding to practice items. The category names used for this test were drawn from the Battig and Montague (1969) and Hunt and Hodge (1971) category norms, along with 2 corresponding category exemplars that made up the study lists (for more detail, see the Stimuli section of Experiment 1). The test list was pseudorandomized such that there were no more than two consecutive categories from the same encoding condition. For each participant, the two exemplars from a given category were members of the same encoding condition (full attention, divided attention, or new) and the same testing condition (inclusion, exclusion). Sets were counterbalanced across participants so that each word appeared equally often in each encoding and testing condition.

\section{Procedure}

The experiment was presented in four phases. The baseline assessment, study phase, and distractor test were identical to those in Experiment 1. After the distractor test, the participants were administered the category association test. Category names were presented in uppercase letters in the center of the computer screen. Three categories that corresponded to practice words were given at the beginning of the test list. Presentation' order of the test list was the same for all participants.

The participants in the indirect test group were told that, for this next task, we were interested in learning more about the types of words that certain categories elicit. They were presented with category names and told to respond to each category label with the first two five- to seven-letter words that were members of that category and that came to mind. No proper nouns or plurals were allowed. No mention was made about the relation between the studied words and the category test. 
Table 3

\begin{tabular}{|c|c|c|c|c|}
\hline \multicolumn{5}{|c|}{$\begin{array}{l}\text { Baseline and Simultaneous Digit-Response Performances for the } \\
\text { Indirect and Inclusion-Exclusion Test Groups (Experiment 2) }\end{array}$} \\
\hline & \multicolumn{4}{|c|}{ Digit-Response Condition } \\
\hline & \multicolumn{2}{|c|}{ Baseline } & \multicolumn{2}{|c|}{ Simultaneous } \\
\hline Performance Measure & $M$ & $95 \% \mathrm{Cl}$ & $M$ & $95 \% \mathrm{CI}$ \\
\hline \multicolumn{5}{|c|}{ Indirect Test Group } \\
\hline Reaction time (msec) & 714.20 & $687.48-741.92$ & 781.68 & $754.46-808.90$ \\
\hline Accuracy rate & 97.36 & $96.09-98.63$ & 95.69 & $94.42-96.96$ \\
\hline \multicolumn{5}{|c|}{ Inclusion-Exclusion Test Group } \\
\hline Reaction time (msec) & 747.83 & $723.19-772.47$ & 826.33 & $801.69-850.97$ \\
\hline Accuracy rate & 97.61 & $95.79-99.43$ & 93.10 & $91.28-94.92$ \\
\hline
\end{tabular}

Note $-\mathrm{Cl}=$ confidence interval.

The participants in the inclusion-exclusion test group were told that their memory for the words presented during the study phase of the experiment was to be tested. The participants were presented with category names on the computer that were accompanied by either the word old or the word new. The word old or new was presented above and to the left of the category name. In the inclusion condition $(o l d)$, the participants were told to respond to each category name with two instances of the category that had been presented in the word lists. If they could not think of an old word, they were to produce the first two appropriate instances of the category that came to mind. In the exclusion condition (new), the participants were told to come up with two novel instances of the category (i.e., category exemplars that had not been presented as study items). As in Experiment 1, for both the inclusion condition and the exclusion condition, the participants were encouraged to first use the category names as cues for direct retrieval of studied category exemplars (see Jacoby, Yonelinas, \& Jennings, 1997). All words were to be five to seven letters in length, and no proper names or plurals were allowed. Half of the category names representing category exemplars in the full-encoding, divided-encoding, new-words, and filleritem conditions were presented with the word old, and half were presented with the word new. Presentation of the words old and new was counterbalanced across two test lists so that each category label served equally often in the inclusion and exclusion test conditions.

For the indirect and inclusion-exclusion test groups, if the participant's response met the response criteria (i.e., two members of the category, five to seven letters in length, not a proper noun or a plural), the experimenter pressed a key that removed the category name and initiated the next trial. Otherwise, the participants were informed of their errors and were told to give a satisfactory completion for the category name. The participants were allowed a maximum of $40 \mathrm{sec}$ to name two category exemplars. If the category exemplars were not generated within the allotted time, the computer automatically advanced to the next trial.

Posttest Awareness Interview. Using a procedure similar to that in Experiment 1, test awareness of the indirect group was assessed following completion of the category association task.

\section{Digit-Response Task}

Table 3 presents the mean and $95 \%$ CIs for the baseline and simultaneous digit-response performances as a function of test group. For the indirect and inclusionexclusion test groups, the participants displayed faster RTs and had higher accuracy rates in the baseline condition than in the simultaneous task condition. These results indicate that the digit-response task was an attentiondemanding task that could not simply be performed auto- matically with the word-reading task. Both groups were, however, able to keep their concurrent digit-response performance within the expected goal of $100 \mathrm{msec}$ and 5 percentage points of their baseline performance, suggesting that the participants were treating the digit-response task as their primary task in the divided-task condition.

\section{Category Association Task}

Table 4 presents the probability of responding with an old word as a function of experimental condition for the category association task. At study, the participants in the indirect and inclusion-exclusion test groups made few errors in reading the words: 5 and 3 errors, respectively.

Indirect test analyses. The data from the indirect test group revealed that the probability of producing a category exemplar from the study list was greater in the fullattention condition $(.18)$ than in the divided-attention condition $(.14)[t(35)=2.13, p<.05]$. Responding to category names with studied category exemplars was above baseline (.09) for items encoded in both attention conditions $[t \mathrm{~s}(35)>3.40]$. However, before concluding that dividing attention at encoding decreases performance on conceptual indirect tests when attentional load is sufficiently resource demanding, data from the posttest interviews were examined. The posttest interviews revealed that only $11(31 \%)$ of the participants spontaneously reported an awareness of a relationship between the study list and the category association test. Of these participants, only $7(19 \%)$ reported that they had used conscious retrieval when completing the category association task. Removing the intentional retrievers from the data analysis did not change the pattern of the findings [i.e., full (.16) > divided (.13)]

PDP analyses. A two-way ANOVA of the inclusionexclusion data revealed significant main effects of test instruction $\left[F(1,35)=32.14, M S_{\mathrm{e}}=0.44, p<.001\right]$ and encoding condition $\left[F(1,35)=29.48, M S_{\mathrm{e}}=0.26, p<.01\right]$. There was also a significant encoding condition $X$ test instruction interaction $\left[F(1,35)=9.06, M S_{\mathrm{e}}=0.12, p=.005\right]$. In the inclusion condition, a greater proportion of studied category exemplars was given to complete category names in the full-attention condition (.30) than in the dividedattention condition $(.16)[t(35)=4.65, p<.001]$. This 


\begin{tabular}{|c|c|c|c|}
\hline \multirow[b]{2}{*}{$\begin{array}{l}\text { Performance } \\
\text { Measure }\end{array}$} & \multicolumn{3}{|c|}{ Study Processing } \\
\hline & $\begin{array}{c}\text { Full } \\
\text { Attention }\end{array}$ & $\begin{array}{c}\text { Divided } \\
\text { Attention }\end{array}$ & New \\
\hline \multicolumn{4}{|l|}{ Test } \\
\hline Indirect & .18 & .14 & .09 \\
\hline Inclusion & .30 & .16 & .06 \\
\hline Exclusion & .14 & .11 & .08 \\
\hline \multicolumn{4}{|l|}{ Estimate } \\
\hline Controlled & .17 & .05 & \\
\hline Automatic & $.16(.17)$ & $.11(.12)$ & \\
\hline
\end{tabular}

Note-Numbers in parentheses are estimates computed after removing the data of 5 subjects whose performance was zero in either the full $(n=2)$ or divided $(n=3)$ exclusion condition. Base rate for inclusion/exclusion group $=.07$

difference was greatly reduced in the exclusion condition $(.14$ vs. . 11$)[t(35)=1.69, p=.10]$.

As in Experiment 1, before computing the estimates of $\mathrm{C}$ and $\mathrm{A}$, I checked to see whether response strategies differed across the inclusion and exclusion conditions. A $t$ test analysis showed that categories were completed with new words equally often in the inclusion $(.06)$ and exclusion $(.08)$ conditions $[t(35)<-1.55]$. Consequently, scores were collapsed across the test instruction conditions to yield a baseline value of .07 . Estimates of $\mathrm{C}$ and A derived using the PDP showed that divided attention (.05), relative to full attention (.17), during study reduced the probability of later consciously controlled recollection $[t(35)=3.01, p<.005]$. More importantly, the analyses also revealed that divided attention (.11), relative to full attention (.16), at encoding reduced estimates of $\mathrm{A}[t(35)=$ $3.25, p<.005]$. Estimates of A were significantly above baseline (.07) for the full- and divided-attention conditions $[t \mathrm{~s}(35)>7.50]$.

In the exclusion test condition, 5 participants produced no intrusions of items that had been studied in either the full-attention condition $(n=2)$ or divided-attention condition $(n=3)$. To avoid artificially lowering the estimates of A (see Jacoby, 1991; Toth et al., 1994), I recalculated the automatic contributions after eliminating the data of the 5 participants who had produced floor effects. This resulted in A estimates of .17 in the full-attention condition and .12 in the divided-attention condition. Subtracting baseline performance from these estimates provided an index of the automatic influences produced by our specific study experience (see Jacoby et al., 1993). By comparing the two adjusted estimates, I found that the parameters representing automatic influences on later category association were greater for words encoded in the fullattention condition (.10) than in the divided-attention condition $(.05)[t(30)=3.20, p<.003]$.

Multinomial model analyses. Although the base rate differences between the inclusion (.06) and exclusion (.08) conditions did not differ statistically, they were also not identical. To assess whether this descriptive base rate dif- ference could have had an influence on the estimates of the memory parameters, I reanalyzed the data using a directretrieval multinomial model that allowed for base rate differences to be taken into account ${ }^{3}$ (adopted from Buchner et al., 1995, and used by Jacoby, 1998; see Appendix A). This model includes three independent processes: consciously controlled processes, automatic processes, and a guessing process $(\mathrm{G})$. Six parameters were used, and the generated parameter estimates were as follows: $\mathrm{C}_{\text {full }}=.17$, $\mathrm{C}_{\mathrm{div}}=.07 ; \mathrm{A}_{\mathrm{full}}=.10, \mathrm{~A}_{\mathrm{div}}=.04 ; \mathrm{G}_{\mathrm{inc}}=.06$, and $\mathrm{G}_{\mathrm{exc}}=08$. The frequency data underlying these parameters are reported in Appendix B. There were a total of 3,024 observations ( 36 participants $\times 84$ observations/participant).

To assess the effect of the attentional manipulation on the parameter estimates of $\mathrm{C}$ and $\mathrm{A}, \mathrm{I}$ tested restricted versions of the model, where $C_{\text {full }}=C_{\text {div }}$, and $A_{\text {full }}=A_{\text {div }}$. To test the fits of the model to the data, the maximumlikelihood ratio statistics $\left(G^{2}\right)$ were computed using the AppleTree program (Rothkegel, 1998) and compared against a chi-square distribution with 1 degree of freedom. To obtain the critical level of $\chi^{2}$, I used the GPOWER program made available by Erdfelder, Faul, and Buchner (1996). This analysis required the input of the following parameters: $w$ (the effect size for chi-square tests; Cohen, 1977), alpha, $N$, and the degrees of freedom. Because of the large number of observations $(n=3,024)$, alpha was set at a more conservative level of .01 . We fixed $w$ at .10, and there was 1 degree of freedom. The power analysis yielded $\chi_{\text {crit }}^{2}(1)=6.63$ and $B=.0027$ (power $=.9983$ ). If the parameter estimates of $C$ and $A$ are both affected by the divided-attention manipulation, then neither model (i.e., $C_{\text {full }}=C_{\text {div }}$ or $A_{\text {full }}=A_{\text {div }}$ ) should fit the data. The results revealed that the attentional manipulation affected $\mathrm{C}$ [the restricted model failed to fit the data, $G^{2}(1)=$ 9.88] and, to a lesser extent, A [the $G^{2}$ statistic approached the critical value, $\left.G^{2}(1)=6.52\right]$. These results replicate those of the ANOVA carried out in the previous section. Furthermore, the parameter estimates of $\mathrm{C}$ and $\mathrm{A}$ generated using the multinomial model $\left(\mathrm{C}_{\mathrm{full}}=.17, \mathrm{C}_{\mathrm{div}}=.07\right.$; $\left.\mathrm{A}_{\text {full }}=.10, \mathrm{~A}_{\mathrm{div}}=.04\right)$ were very similar to those derived using the PDP procedure $\left(\mathrm{C}_{\text {full }}=.17, \mathrm{C}_{\mathrm{div}}=.05 ; \mathrm{A}_{\text {full }}=\right.$ $.10, \mathrm{~A}_{\mathrm{div}}=.05$ ).

\section{Discussion}

Using the PDP, it was found that, for recall cued with category names, manipulating the amount of attention available at encoding affected the parameter estimates of both $\mathrm{C}$ and $\mathrm{A}$. Consistent with previous findings (e.g., Mulligan, 1997, 1998; Mulligan \& Hartman, 1996; Schmitter-Edgecombe, 1996a), the data from the indirect testing condition also revealed that attentional resources at learning played a role in supporting subsequent performance on the conceptual indirect test. The effect of the attentional manipulation on the indirect test was not an artifact of contamination from conscious retrieval processes. The same effect was found in the estimate of automatic memory processes using the PDP. Apparently, having full attention available during learning helps en- 
sure that semantic information is processed. The availability of semantic information may then benefit subsequent automatic influences of memory when retrieval is cued with a conceptually driven task.

Divided attention at encoding is thought to reduce the amount of semantic elaboration or conceptual processing that can occur during study (see e.g., Craik, 1983; Craik $\&$ Byrd, 1982). It appears that the processes that support conceptual priming, like those that support conscious retrieval, make demands on attentional resources at encoding and may benefit from the opportunity to encode information to a deeper level at learning. Several studies have shown that semantic elaboration can increase priming on conceptual tests (e.g., Hamann, 1990; Rappold \& Hashtroudi, 1991; Srinivas \& Roediger, 1990). Mecklenbrauker, Wippich, and Mohrhusen (1996) demonstrated a levels-of-processing effect when they used indirect test instructions and a category association test. In contrast, when they used the PDP, they found positive effects of semantic processing on the parameter estimates of controlled, but not automatic uses of memory. Rather than concluding that the positive effects of deep encoding observed for conceptual priming were due to contamination by explicit retrieval strategies, these authors pointed out possible limitations to the PDP procedure. They also indicated that their participants may have relied more on a generate/recognize strategy than on a direct-retrieval strategy, suggesting that assumptions for use of the PDP may have been violated (Jacoby, 1998). The results from the present PDP analyses are consistent with the idea that conceptual priming involves a facilitation in processing information that is based on access to meaning and that conceptually driven processing may tap semantic forms of memory (see Schacter, 1990, 1992a, 1992b).

\section{GENERAL DISCUSSION}

Using the PDP, it was demonstrated that division of attention during learning reduced estimates of the parameters representing automatic memory processes when retrieval was cued with category names (conceptually driven task) but not when it was cued with word stems (perceptually driven task). Consistent with these findings, the indirect testing results also showed that decreasing attention available at learning reduced performance on the category association test but not the stem completion test. Previous studies that have used indirect testing conditions have also found evidence to suggest that division of attention at learning may affect subsequent performance on conceptual, but not perceptual, indirect tests (e.g., Mulligan \& Hartman, 1996). The possibility, however, has been raised that such findings reflect the potential for conceptual indirect measures to be more easily contaminated by intentional retrieval than perceptual indirect measures. Using both an indirect test procedure and the PDP, the present results support the notion that, in contrast to perceptual priming, attentional resources at learning play an important role in conceptual priming. Conceptual priming appears to be sensitive to semantic processing and enhanced by the opportunity to encode information to a deeper level at learning.

With respect to the role of attention at learning, conceptual indirect memory appears to be more similar to direct memory than to perceptual indirect memory. Reducing the amount of attention available at learning decreased priming on the category association test and decreased estimates of the parameters representing controlled and automatic memory processes for recall cued with category names (conceptually driven task). In contrast, the dividedattention manipulation had no effect on perceptual priming or on the parameter estimates of automatic memory processes for recall cued with word stems (perceptually driven task). Other manipulations have also been found to dissociate conceptual and perceptual indirect tests but to have similar effects on conceptual indirect and direct memory measures. For example, researchers have reported that encoding elaborations (like levels-of-processing, generation, and organization) influence performance on conceptual indirect and direct tests but have little effect on perceptual indirect tests (Hamann, 1990; Srinivas \& Roediger, 1990). The present results are also consistent with a growing body of literature that suggests that conceptual indirect memory measures and direct tests may be mediated by some similar processes, which are different from those involved in perceptual indirect tests (Mulligan, 1997; Roediger, Weldon, \& Challis, 1989; Wagner, Gabrieli, \& Verfaellie, 1997).

The present data are incompatible with the idea that performance on all indirect measures reflects automatic encoding processes, whereas performance on direct memory tests reflects encoding processes that require attentional resources. It appears that attentional resources play an important role in later conceptual indirect memory, but they play little or no role in perceptual indirect memory. In relation to the neurologic literature, studies are consistent in demonstrating normal or near-normal perceptual priming in neurologically impaired populations, such as patients with amnesia and closed-head injury, who exhibit deficits on direct memory tests (e.g., SchmitterEdgecombe, 1996b; Shimamura, 1986). In contrast, the results concerning performance on conceptual indirect tasks have been somewhat inconsistent. While some studies have found impaired performance on conceptual indirect tests in populations of amnesic and closed-head injured patients (e.g., Fahy, Marks, Schmitter-Edgecombe, \& Long, 1995; Keane et al., 1997; Vakil \& Sigal, 1997), other studies have not (e.g., Cermak et al., 1995; Graf, Shimamura, \& Squire, 1985; Shum et al., 1996).

If performance on conceptual indirect memory measures is sensitive to manipulations that affect the conceptual encoding process (e.g., semantic vs. nonsemantic encoding; full vs. divided attention), then the question that remains is, "Why do we sometimes see intact conceptual priming in neurologically impaired populations that are thought to have difficulty engaging in self-directed, elaborative encoding (e.g., Cermak, Butters, \& Gerrein, 1973; Goldstein, Levin, Boake, \& Lohrey, 1990)?" One explanation may be that, in most indirect testing situations, 
participants are not told to engage in intentional memory processes during learning (see Keane et al., 1997). It is therefore likely that, in most incidental study situations, both the neurologically impaired group and the control group are engaging in similar levels of encoding, typically shallow encoding, as directed by the encoding question. This type of incidental encoding most likely does not require self-directed initiation or significant attentional resources, since participants do not have to go beyond answering the encoding questions. Consistent with this idea, Keane et al. (1997) have recently found that amnesic patients, who exhibited a normal levels-of-processing effect on a category association test, showed levels of conceptual priming on the category test commensurate, with controls following incidental but not intentional encoding. In this situation, the conceptual priming impairment may reflect a deficit in the encoding phase- that is, in the tendency of the amnesic patients' to engage in less self-directed elaborative encoding than controls-rather than a deficit in the retrieval phase.

While the present results suggest that conceptual and perceptual priming may be supported by different attentional encoding requirements, it should be kept in mind that not all attentional manipulations are equivalent. The digit-response task used in the present study was designed to be sufficiently resource demanding but to still allow for the perceptual analysis necessary for word identification to be carried out. The digit-response task presumably decreased the general pool of attentional resources that the participants had available to allocate to the encoding process. It remains to be investigated whether similar findings would occur if an attentional manipulation that interrupted the perceptual analysis process were employed. The present study also used a more perceptually driven orienting task (i.e., reading) that did not incidentally induce significant elaborative encoding during learning. However, the participants may have engaged in some self-directed elaborative encoding as a result of the fact they were informed that they would be asked to make up a story using words from the word lists. Future studies may want to replicate the results using a more conceptually driven orienting task (e.g., generation).

Although converging results were found for the indirect memory measures and the PDP, the results also illustrate that posttest questionnaires should routinely be used in conjunction with indirect tests. For the stem completion task, $22(61 \%)$ of the participants spontaneously reported an awareness of producing target words when completing the stem task, and $18(50 \%)$ of the participants reported that they had intentionally used conscious retrieval. Furthermore, when the data from only the intentional retrievers were analyzed, the results revealed the opposite finding - that is, that decreasing attention at learning significantly reduced perceptual priming. This illustrates that conscious retrieval strategies can contaminate performance on indirect tests and that inaccurate conclusions can be drawn, especially if the majority of participants utilize conscious retrieval strategies (see also Wolters \& Prinsen, 1997). For the category association test, there were only 11 test-aware participants $(31 \%)$ and 7 participants (19\%) who reported using a conscious retrieval strategy. The small number of intentional retrievers for this test is in contrast to the prediction that explicit retrieval strategies would more easily contaminate performance on conceptual indirect tests, relative to perceptual indirect tests. While some studies have found a similar low rate of test-aware participants $(29 \%)$ when using the category association procedure (Schmitter-Edgecombe, 1996a), other studies, such as the Mulligan and Hartman study (1996, Experiment 1), have found the percentage of test-aware participants to be as high as $93 \%$ (Mulligan \& Hartman, 1996). Differences between the present study and the Mulligan and Hartman study include the number of exemplars presented per category to participants at study ( 2 as opposed to 6 ) and the number of exemplars produced per category by participants at test ( 2 as opposed to 8). It may be that participants are less likely to discover a relation between study and test when fewer exemplars are presented per category at study, when fewer responses are required per category at test, and when the processes engaged at encoding differ significantly from the processes engaged at retrieval. Consistent with these ideas, posttest questionnaire data from a recent study by Mulligan (1998, Experiment 2) revealed a low rate of testaware participants $(19 \%)$ when they assessed implicit memory for previously studied words using a conceptual indirect word association test that required only one associate to be generated for each test stimulus. Thus, in addition to underscoring the importance of posttest questionnaires and to suggesting factors that may increase participants' test awareness on indirect tests, the present results suggest that the development of procedures that allow for the computations of unbiased estimates of automatic memory processes is important.

One empirical prediction of the PDP is that when conscious recollection is close to zero, parameter estimates of automatic memory processes should approximate performance on an indirect test (Reingold \& Goshen-Gottstein, 1996). This is because, under such conditions, the indirect memory test could be expected to reflect a relatively uncontaminated measure of automatic, unconscious influences. As seen in Tables 2 and 4, conscious control was minimal in the divided-attention conditions for both the stem completion test and the category association test, making it possible to compare the parameter estimates of automatic memory processes derived using the PDP with indirect performance. Indirect performance was .28 and .14 for the stem completion and category association tests, respectively, and the corresponding automatic memory estimates were .26 and .12 . Consistent with previous process-dissociation research (e.g., Reingold \& Goshen-Gottstein, 1996; Toth et al., 1994), the present findings show that estimates of automatic memory influences gained by relying on the independence assumption almost perfectly match performance on indirect tests that are relatively uncontaminated by intentional uses of memory. Although the present findings converge with indirect memory research, they are based on the validity of the PDP, whose assumptions have been 
challenged (e.g., Curran \& Hintzman, 1995, 1997; Dodson \& Johnson, 1996; Komatsu, Graf, \& Uttl, 1995).

In conclusion, using the PDP, it was demonstrated that parameter estimates of automatic memory were affected by divided attention at encoding when retrieval was cued with a conceptually driven task but not a perceptually driven task. While the present findings are consistent with the transfer-appropriate processing framework, which emphasizes the distinction between conceptual and perceptual processes (for more information, see Blaxton, 1989, and Mulligan \& Hartman, 1996), they can also be explained within an attentional framework. In contrast to the relatively automatic, presemantic activation processes that support later perceptual priming, attentional resources at learning play an important role in conceptual priming.

\section{REFERENCES}

BadDEley, A. D., \& Hitch, G. (1974). Working memory. In G. H Bower (Ed.), The psychology of learning and motivation (Vol. 8, pp. 47-90). New York: Academic Press.

Baddeley, A. D., Scott, D., Drynan, R., \& SMith, J. (1969). Shortterm memory and the limited capacity hypothesis. British Journal of Psychology, 60, 51-55.

BARTZ, W. H., \& SALEHI, M. (1970). Interference in short- and longterm memory. Journal of Experimental Psychology, 84, 380-382.

Bassili, J. N., SMiTh, M. C., \& MacLEOD, C. M. (1989). Auditory and visual stem completion: Separating data-driven and conceptuallydriven processes. Quarterly Journal of Experimental Psychology, 41A, 439-453.

Battig, W. F., \& MontagUe, W. E. (1969). Category norms for verbal items in 56 categories: A replication and extension of the Connecticut category norms. Journal of Experimental Psychology Monographs, 80(3, Pt. 2).

BENNET, B., \& MURDOCK, B. (1965). Effects of subsidiary task on short-term memory. British Journal of Psychology, 56, 413-419.

Bentin, S., Moscovitch, M., \& Heth, I. (1992). Memory with and without awareness: Performance and electrophysiological evidence of savings. Journal of Experimental Psychology: Learning, Memory, \& Cognition, 18, 1270-1283.

BLAXTON, T. A. (1989). Investigating dissociation among memory measures: Support for a transfer-appropriate processing framework. Journal of Experimental Psychology: Learning, Memory, \& Cognition, 15, 657-668.

Buchner, A., Erdfelder, E., \& Vaterrodt-Plunnecke, B. (1995). Toward unbiased measurement of conscious and unconscious memory processes within the process-dissociation framework. Journal of Experimental Psychology: General, 124, 137-160.

Buckner, R. L., Petersen, S. E., Ojemann, J. G., Miezin, F. M., SQuire, L. R., \& Raichle, M. E. (1995). Functional anatomical studies of explicit and implicit memory retrieval tasks. Journal of Neuroscience, 15, 12-29.

Cermak, L. S. (1993). Automatic versus controlled processing and the implicit task performance of amnesic patients. In P. Graf \& M. E. J. Masson (Eds.), Implicit memory: New directions in cognition, development, and neuropsychology (pp. 287-302). Hillsdale, NJ: Erlbaum.

Cermak, L. S., Butters, N., \& Gerrein, J. (1973). The extent of the verbal encoding ability of Korsakoff patients. Neuropsychologia, 11, 85-94.

Cermak, L. S., Verfaellie, M., \& Chase, K. A. (1995). Implicit and explicit memory in amnesia: An analysis of data-driven and conceptuallydriven processes. Neuropsychology, 9, 281-290.

COHEN, J. (1977). Statistical analysis for the behavioral sciences (rev. ed.). New York: Academic Press.

Cowan, N., \& StadleR, M. A. (1996). Estimating unconscious processes: Implications of a general class of models. Journal of Experimental Psychology: General, 125, 195-200.

CRAIK, F. I. M. (1983). On the transfer of information from temporary to permanent memory. Philosophical Transactions of the Royal Society of London: Series B, 302, 155-158.

CraIK, F. I. M., \& BYRD, M. (1982). Aging and cognitive deficits: The role of attentional resources. In F. I. M. Craik \& S. E. Trehub (Eds.), Aging and cognitive processes (pp. 191-211). New York: Plenum. Curran, T., \& Hintzman, D. L. (1995). Violations of the independence assumption in process-dissociation. Journal of Experimental Psychology: Learning, Memory, \& Cognition, 21, 531-547.

Curran, T., \& Hintzman, D. L. (1997). Consequences and causes of correlations in process dissociation. Journal of Experimental Psychology: Learning, Memory, \& Cognition, 23, 496-504.

Dodson, C. S., \& Johnson, M. K. (1996). Some problems with the process-dissociation approach to memory. Journal of Experimental Psychology: General, 125, 181-194.

ERdFELdER, E., FAUL, F., \& BUCHNER, A. (1996). GPOWER: A general power analysis program. Behavior Research Methods, Instruments, \& Computers, 28, 1-11.

Fahy, J. F., Marks, W., Schmitter-Edgecombe, M., \& Long, C. J. (1995). Dissociations among memory tests after severe closed head injury: Systems theory versus a processing account. Journal of the International Neuropsychological Society, 1, 183.

Goldstein, F. C., Levin, H. S., BoAke, C., \& Lohrey, J. H. (1990). Facilitation of memory performance through induced semantic processing in survivors of severe closed head injury. Journal of Clinical \& Experimental Psychology, 12, 286-300.

Graf, P., \& Komatsu, S. (1994). PDP: Handle with caution! European Journal of Cognitive Psychology, 6, 113-129.

GRAF, P., \& SCHACTER, D. L. (1985). Implicit and explicit memory for new associations in normal and amnesic subjects. Journal of Experimental Psychology: Learning, Memory, \& Cognition, 11, 501-518.

Graf, P., Shimamura, A. P., \& SQuire, L. R. (1985). Priming across modalities and priming across category levels: Extending the domain of preserved function in amnesia. Journal of Experimental Psychology, Learning, Memory, \& Cognition, 11, 386-396.

GREENE, R. L. (1986). Word stems as cues in recall and completion tasks. Quarterly Journal of Experimental Psychology, 38A, 663-674.

HAIST, F., MUSEN, G., \& SQUiRe, L. R. (1991). Intact priming of words and nonwords in amnesia. Psychobiology, 19, 275-285.

HAMANN, S. B. (1990). Level-of-processing effects in conceptually driven implicit tasks. Journal of Experimental Psychology: Learning, Memory, \& Cognition, 16, 970-977.

HAMANN, S. B., \& SQUIRE, L. R. (1996). Level-of-processing effects in word-completion priming: A neuropsychological study. Journal of Experimental Psychology: Learning, Memory, \& Cognition, 22, 933-947.

HAY, J. F., \& JACOBY, L. L. (1996). Separating habit and recollection: Memory slips, process dissociations, and probability matching. Journal of Experimental Psychology: Learning, Memory, \& Cognition, 22, 1323-1335.

Hintzman, D. L., \& CuRRan, T. (1997). More than one way to violate independence: Reply to Jacoby and Shrout (1997). Journal of Experimental Psychology: Learning. Memory, \& Cognition, 23, 511-513.

Hunt, K. P., \& Hodge, M. H. (1971). Category-item frequency and category-name meaningfulness $\left(m^{\prime}\right)$ : Taxonomic norms for 84 categories. Psychonomic Monograph Supplements, 4(6, Whole No. 54), 97-121.

IIINGRINI, M., VAZOU, F., \& LEROY, P. (1995). Dissociation of implicit and explicit memory tests: Effect of age and divided attention on category exemplar generation and cued recall. Memory \& Cognition, 23, 462-467.

JACOBY, L. L. (1991). A process-dissociation framework: Separating automatic from intentional uses of memory. Journal of Memory \& Language, 30, 513-541.

JACOBY, L. L. (1998). Invariance in automatic influences of memory: Toward a user's guide for the PDP. Journal of Experimental Psychology: Learning, Memory, \& Cognition, 24, 3-26.

JACOBY, L. L., BEGG, I. M., \& TOTH, J. P. (1997). In defense of functional independence: Violations of assumptions underlying the PDP? Journal of Experimental Psychology: Learning. Memory, \& Cognition, 23, 484-495.

JACOBY, L. L., \& SHROUT, P. E. (1997). Toward a psychometric analysis of violations of the independence assumption in process dissociation. Journal of Experimental Psychology: Learning, Memory, \& Cognition, 23, 505-510. 
JAcoby, L. L., Toth, J. P., \& Yonelinas, A. P. (1993). Separating conscious and unconscious influences of memory: Measuring recollection. Journal of Experimental Psychology: General, 122, 139-154.

JACOBY, L. L., WoloshYN, V., \& KelleY, C. (1989). Becoming famous without being recognized: Unconscious influences of memory produced by dividing attention. Journal of Experimental Psychology General, 118, 115-125.

JACOBY, L. L., Yonelinas, A. P., \& Jennings, J. M. (1997). The relation between conscious and unconscious (automatic) influences: Toward showing independence. In J. Cohen \& J. Schooler (Eds.), Scientific approaches to the question of consciousness (pp. 13-47). Mahwah, NJ: Erlbaum.

Joordens, S., \& MerikLe, P. M. (1993). Independence or redundancy? Two models of conscious and unconscious influences. Journal of Experimental Psychology: General, 122, 462-467.

Keane, M. M., Gabrieli, J. D. E., Monti, L. A., Fleischman, D. A., Cantor, J. M., \& Noland, J. S. (1997). Intact and impaired conceptual memory processes in amnesia. Neuropsychology, 11, 59-69.

Komatsu, S., Graf, P., \& UTTL, B. (1995). PDP: Core assumptions fail, sometimes. European Journal of Cognitive Psychology, 7, 19-40.

Koriat, A., \& Feuerstein, N. (1976). The recovery of incidentally acquired information. Acta Psychologica, 4, 71-80.

KUČERA, H., \& FrANCIS, W. N. (1967). Computational analysis of present-day American English. Providence, RI: Brown University Press.

MCKone, E., \& SLEE, J. A. (1997). Explicit contamination in "implicit" memory for new associations. Memory \& Cognition, 25, 352-366.

Mecklenbrauker, S., Wippich, W., \& Mohrhusen, S. H. (1996) Conscious and unconscious influences of memory in a conceptual task: Limitations of a process-dissociation procedure. Swiss Journal of Psychology, 55, 34-48.

Mulligan, N. W. (1997). Attentional and implicit memory tests: The effects of varying attentional load on conceptual priming. Memory \& Cognition, 25, 11-17.

Mulligan, N. W. (1998). The role of attention during coding on implicit and explicit memory. Journal of Experimental Psychology. Learning, Memory, \& Cognition, 24, 27-47.

Mulligan, N. W., \& Hartman, M. (1996). Divided attention and indirect memory tests. Memory \& Cognition, 24, 453-465.

Mulligan, N. W., \& Hirshman, E. (1997). Measuring the bases of recognition memory: An investigation of the process-dissociation framework. Journal of Experimental Psychology: Learning, Memory, \& Cognition, 23, 280-304

MutTer, S. A., Howard, D. V., Howard, J. H., \& Wiggs, C. L. (1990) Performance on direct and indirect tests of memory after mild closed head injury. Cognitive Neuropsychology, 7, 329-346.

PARKIn, A. J., ReID, T. K., \& Russo, R. (1990). On the differential nature of implicit and explicit memory. Memory \& Cognition, 18, 507-514.

Parkin, A. J., \& Russo, R. (1990). Implicit and explicit memory and the automatic/effortful distinction. European Journal of Cognitive Psychology, 2, 71-80.

Perruchet, P., \& Baveux, P. (1989). Correlational analyses of explicit and implicit memory performance. Memory \& Cognition, 17, 77-86.

RAPPOLD, V. A., \& HASHTROUDI, S. (1991). Does organization improve priming? Journal of Experimental Psychology: Learning, Memory, \& Cognition, 17, 103-114.

ReINGoLd, E. M., \& GoShen-GotTstein, Y. (1996). Separating consciously controlled and automatic influences in memory for new associations. Journal of Experimental Psychology: Learning, Memory \& Cognition, 22, 387-406.

RichaRdSON-KLAVEHN, A., \& BJORK, R. A. (1988). Measures of memory. Annual Review of Psychology, 39, 475-453.

ROEDIGER, H. L., III (1990). Implicit memory: Retention without remembering. American Psychologist, 45, 1043-1056.

RoEdiger, H. L., III, Weldon, M. S., \& Challis, B. H. (1989). Explaining dissociations between implicit and explicit measures of retention: A processing account. In H. L. Roediger III \& F. I. M. Craik (Eds.), Varieties of memory and consciousness: Essays in honour of Endel Tulving (pp. 3-36). Hillsdale, NJ: Erlbaum

Roediger, H. L., III, Weldon, M. S., Stadler, M. L., \& Riegler, G. L. (1992). Direct comparison of two implicit memory tests: Word frag- ment and word-stem completion. Journal of Experimental Psychology: Learning, Memory, \& Cognition, 18, 1251-1269.

RoTHKEGEL, R. (1998). AppleTree statistical inference program for multinomial binary tree models (Version 1.2.0) [Computer software]. Trier: University of Trier.

SCHACTER, D. L. (1987). Implicit memory: History and current status. Journal of Experimental Psychology: Learning, Memory, \& Cognition, 13, 501-518.

SCHACTER, D. L. (1990). Perceptual representation systems and implicit memory: Toward a resolution of the multiple memory systems debate. In A. Diamond (Ed.), Development and neural bases of higher cognitive function (Annals of the New York Academy of Sciences, Vol. 608, pp. 543-571). New York: New York Academy of Sciences.

SCHACTER, D. L. (1992a). Priming and multiple memory systems: Perceptual mechanisms of implicit memory. Journal of Cognitive Neuroscience, 4, 244-256.

SCHACTER, D. L. (1992b). Understanding implicit memory: A cognitive neuroscience approach. American Psychologist, 47, 559-569.

SCHMitTER-EDGecombE, M. (1996a). The effects of divided attention on implicit and explicit memory performance. Journal of the International Neuropsychological Society, 2, 111-125.

SCHMitTER-EDgecombe, M. (1996b). Effects of divided attention on implicit and explicit memory performance following severe closed head injury. Neuropsychology, 10, 155-167.

Shimamura, A. P. (1986). Priming effect in amnesia: Evidence for a dissociable memory function. Quarterly Journal of Experimental Psychology, 38, 619-644.

Shum, D., SWeeper, S., \& Murray, R. (1996). Performance on verbal implicit and explicit memory tasks following traumatic brain injury. Journal of Head Trauma Rehabilitation, 11, 43-53.

SMith, E. R., \& Branscombe, N. R. (1988). Category accessibility as implicit memory. Journal of Experimental Social Psychology, 24, 490-504.

Souire, L. R., Ojemann, J. G., Miezin, F. M. Petersen, S. E., Videen, T. O., \& RAICHLE, M. E. (1992). Activation of the hippocampus in normal humans: A functional anatomical study of memory. Proceedings from the National Academy of Neuroscience, 89, 1837-1841.

SRINIVAS, K., \& RoEDIGER, H. L., III (1990). Classifying implicit memory tests: Category association and anagram solution. Journal of Memory \& Language, 29, 389-412.

TOTH, J. P., ReINGOLD, E. M., \& JACOBY, L. L. (1994). Toward a redefinition of implicit memory: Process dissociations following elaborative and self-generation. Journal of Experimental Psychology: Learning, Memory, \& Cognition, 20, 290-303.

Toth, J. P., Reingold, E. M., \& JACOBY, L. L. (1995). A response to Graf and Komatsu's (1994) critique of the PDP: When is caution necessary? European Journal of Cognitive Psychology, 7, 113-130.

Tulving, E., \& Schacter, D. L. (1990). Priming and human memory systems. Science, 247, 301-305.

VAKIL, E., \& Sigal, J. (1997). The effect of level of processing on perceptual and conceptual priming: Control versus closed-head injured patients. Journal of the International Neuropsychological Society, 3 , 327-336.

Wagner, A. D., Gabrieli, J. D. E., \& Verfaellie, M. (1997). Dissociations between familiarity processes in explicit recognition and implicit perceptual memory. Journal of Experimental Psychology: Learning, Memory, \& Cognition, 23, 305-323.

WECHSLER, D. (1981). Manual of the Wechsler Adult Intelligence Scale-Revised. San Antonio: Psychological Corporation.

Wolters, G., \& Prinsen, A. (1997). Full versus divided attention and implicit memory performance. Memory \& Cognition, 25, 764771.

Yonelinas, A. P., \& JACOBY, L. L. (1996). Noncritical recollection: Familiarity as automatic, irrelevant recollection. Consciousness \& Cognition, 5, 131-141

\section{NOTES}

1. The term category association will be used to refer to tasks wherein participants are given category names (e.g., four-footed ani$\mathrm{mal}$ ) and asked to produce exemplars of each category (e.g., dog, cat). 
In the literature, this task has also been referred to as the categoryexemplar production test (e.g., Mulligan \& Hartman, 1996).

2. It should be noted that several studies have found that levels-ofprocessing can affect priming on the stem completion test (e.g., Bassili, Smith, \& Macleod, 1989). However, recent research suggests that such findings may have resulted from contamination of the conceptual indirect measure by intentional uses of memory (see Hamann \& Squire, 1996; Roediger, Weldon, Stadler, \& Riegler, 1992; Toth, Weldon, Stadler, \& Riegler, 1994).

3. The finding of a higher base rate for the inclusion test than for the exclusion test makes it less likely that participants in this study were using a generate/recognize strategy. In comparison with direct-retrieval instruc- tions, generate-recognize instructions have been found to produce poorer performance on the inclusion test but increase the accuracy of exclusion performance (Jacoby, 1998). Reliance on a generate-recognize strategy makes recollection irrelevant for inclusion performance but makes recognition-memory important for the exclusion test (Jacoby, 1998). Additionally, reliance on a generate-recognize strategy would result in performance on the inclusion test being roughly comparable to that on the indirect test. The data revealed a higher probability of completing stems with studied words when encoding occurred under full attention in the inclusion task condition (.30), than in the indirect task condition (.18) $[t(70)=-4.15, p<.001]$. This suggests that intentional retrieval played a larger role in the inclusion test than in the indirect test.

\section{APPENDIX A \\ Direct-Retrieval Model: Adapted from \\ Buchner, Erdfelder, and Vaterrodt-Plunnecke (1995) and Used by Jacoby (1998)}

\begin{tabular}{|c|c|}
\hline \multicolumn{2}{|l|}{ Inclusion Items } \\
\hline $\begin{array}{l}\text { Full-Attention Condition } \\
C_{\text {full }} \times A_{\text {full }} \\
C_{\text {full }} \times\left(1-A_{\text {full }}\right) \\
\left(1-C_{\text {full }}\right) \times A_{\text {full }} \\
\left(1-C_{\text {full }}\right) \times\left(1-A_{\text {full }}\right) \times G_{\text {inc }} \\
\quad\left(1-C_{\text {full }}\right) \times\left(1-A_{\text {full }}\right) \times\left(1-G_{\text {inc }}\right)\end{array}$ & $\begin{array}{l}\text { target solution } \\
\text { target solution } \\
\text { target solution } \\
\text { target solution } \\
\text { nontarget solution }\end{array}$ \\
\hline $\begin{array}{l}\text { Divided-Attention Condition } \\
C_{\text {divided }} \times A_{\text {divided }} \\
C_{\text {divided }} \times\left(1-A_{\text {divided }}\right) \\
\left(1-C_{\text {divided }}\right) \times A_{\text {divided }} \\
\left(1-C_{\text {divided }}\right) \times\left(1-A_{\text {divided }}\right) \times G_{\text {inc }} \\
\left(1-C_{\text {divided }}\right) \times\left(1-A_{\text {divided }}\right) \times\left(1-G_{\text {inc }}\right)\end{array}$ & $\begin{array}{l}\text { target solution } \\
\text { target solution } \\
\text { target solution } \\
\text { target solution } \\
\text { nontarget solution }\end{array}$ \\
\hline $\begin{array}{l}\text { New } \\
\qquad \mathrm{G}_{\text {inc }} \\
\quad\left(1-G_{\text {inc }}\right)\end{array}$ & $\begin{array}{l}\text { target solution } \\
\text { nontarget solution }\end{array}$ \\
\hline Exclusion Items & \\
\hline $\begin{array}{l}\text { Full-Attention Condition } \\
C_{\text {full }} \times A_{\text {full }} \\
C_{\text {full }} \times\left(1-A_{\text {full }}\right) \\
\left(1-C_{\text {full }}\right) \times A_{\text {full }} \\
\left(1-C_{\text {full }}\right) \times\left(1-A_{\text {full }}\right) \times G_{\text {exc }} \\
\left(1-C_{\text {full }}\right) \times\left(1-A_{\text {full }}\right) \times\left(1-G_{e x c}\right)\end{array}$ & $\begin{array}{l}\text { nontarget solution } \\
\text { nontarget solution } \\
\text { target solution } \\
\text { target solution } \\
\text { nontarget solution }\end{array}$ \\
\hline $\begin{array}{l}\text { Divided-Attention Condition } \\
C_{\text {divided }} \times A_{\text {divided }} \\
C_{\text {divided }} \times\left(1-A_{\text {divided }}\right) \\
\left(1-C_{\text {divided }}\right) \times A_{\text {divided }} \\
\left(1-C_{\text {divided }}\right) \times\left(1-A_{\text {divided }}\right) \times G_{\text {exc }} \\
\left(1-C_{\text {divided }}\right) \times\left(1-A_{\text {divided }}\right) \times\left(1-G_{\text {exc }}\right)\end{array}$ & $\begin{array}{l}\text { nontarget solution } \\
\text { nontarget solution } \\
\text { target solution } \\
\text { target solution } \\
\text { nontarget solution }\end{array}$ \\
\hline $\begin{array}{l}\text { New } \\
\qquad \mathrm{G}_{\mathrm{exc}} \\
\left(1-\mathrm{G}_{\mathrm{exc}}\right)\end{array}$ & $\begin{array}{l}\text { target solution } \\
\text { nontarget solution }\end{array}$ \\
\hline
\end{tabular}

\section{APPENDIX B}

Frequency of Target Solution and Nontarget Solution Responses

\begin{tabular}{|c|c|c|c|c|c|c|}
\hline \multirow[b]{3}{*}{ Test Condition } & \multicolumn{6}{|c|}{ Study Processing } \\
\hline & \multicolumn{2}{|c|}{ Full Attention } & \multicolumn{2}{|c|}{ Divided Attention } & \multicolumn{2}{|c|}{ New } \\
\hline & Target & Nontarget & Target & Nontarget & Target & Nontarget \\
\hline Inclusion & $15 \overline{1}$ & $3 \overline{53}$ & 81 & 423 & 30 & 474 \\
\hline Exclusion & 433 & 71 & 449 & 55 & 40 & 464 \\
\hline
\end{tabular}

